\title{
Bi-level Versus Continuous Positive Airway Pressure in Acute Cardiogenic Pulmonary Edema: A Randomized Control Trial
}

\author{
Basant Hamdy El-Refay ${ }^{1}$, Rehab Farrag Gwada ${ }^{2,}$, Bassem S. Ibrahim ${ }^{3}$ \\ ${ }^{1}$ Department of Physical Therapy for Cardiovascular/Respiratory Disorders and Geriatrics, Faculty of Physical Therapy, Cairo University, \\ Giza, Egypt \\ ${ }^{2}$ Department of Physical Therapy, National Heart Institute, Giza, Egypt \\ ${ }^{3}$ Heart Failure Unit, National Heart Institute, Giza, Egypt
}

Email address:

bassanthamdy@yahoo.com (B. H. El-Refay), rehabfarrag40@yahoo.com (R. F. Gwada), bassemi2002@yahoo.co.uk (B. S. Ibrahim)

\section{To cite this article:}

Basant Hamdy El-Refay, Rehab Farrag Gwada, Bassem S. Ibrahim. Bi-level Versus Continuous Positive Airway Pressure in Acute Cardiogenic Pulmonary Edema: A Randomized Control Trial. Clinical Medicine Research. Vol. 4, No. 6, 2015, pp. 221-228.

doi: $10.11648 /$ j.cmr.20150406.19

\begin{abstract}
This study was to compare the efficacy of continuous, bi-level positive airway pressure (CPAP, Bi-PAP) and oxygen therapy on detailed observation of time-course change in blood gases, physiological parameters and rate of endotracheal intubation in patient with acute cardiogenic pulmonary edema (ACPE). Sixty-six patients with ACPE were randomly assigned to receive standard oxygen $\left(\mathrm{O}_{2}\right)$ therapy $(\mathrm{n}=23)$, CPAP $(\mathrm{n}=21)$, and Bi-PAP $(\mathrm{n}=22)$. Blood gases $(\mathrm{PaCO}$, $\mathrm{PaO}_{2}, \mathrm{SaO}_{2}, \mathrm{pH}$, and $\mathrm{HCO}_{3}$ ), and physiological parameters (HR, RR, SBP, and DBP) were collected at baseline (T0), immediately after 60 minutes (T60), and after 30 minutes of discontinuation (T90). A significant improvements ( $<<0.05$ ) in $\mathrm{PaCO}_{2}, \mathrm{PaO}_{2}, \mathrm{SaO}_{2}$ and vital signs were observed immediately after CPAP and Bi-PAP when compared to $\mathrm{O}_{2}$ therapy. After 30 minutes of disconnection, Bi-PAP revealed significant improvement $(\mathrm{p}<0.05)$ in $\mathrm{PaO}_{2}, \mathrm{SaO}_{2}$, and respiratory rate. No differences on intubation and death rate detected among treatment groups. Both methods of noninvasive ventilations are effective treatment for ACPE. However, Bi-PAP should be considered as first line of treatment due to faster and continuous improvement in oxygenation and respiratory rate.
\end{abstract}

Keywords: Continuous Positive Airway Pressure, Bi-level Positive Airway Pressure, Acute Cardiogenic Pulmonary Edema

\section{Introduction}

Acute cardiogenic pulmonary edema (ACPE) is one of the most common conditions presenting to the emergency department. It is associated with higher rate of death, especially when it is coupled with acute myocardial infarction [1-3].

Standardized medical treatment with oxygen therapy, diuretics, and vasodilators could improve the symptom of most of the patients with ACPE. However, a significant number of patients required endotracheal intubation and mechanical ventilation, with its associated potential complications [4] Consequently, may prolong intensive care unit (ICU) and hospital stay.

Over the past three decades, application of noninvasive ventilation (NIV) either with continuous positive airway pressure (CPAP) or Bi-level positive airway pressure (BiPAP) has been used with the standardized medical treatment as an effective therapeutic approach to treat ACPE [5-10].

The goals of NIV use in the treatment of ACPE are to improve oxygenation, reduce the effort of breathing and increase cardiac output and decreased left ventricular preand after-load [5-8].

Many studies revealed that, CPAP improved arterial oxygenation $\left(\mathrm{PaO}_{2}\right)$, and reduces endotracheal intubation rate [9-11] and mortality rate in ACPE [12, 13]. However, other studies failed to show these effects [14-16]. As compared with CPAP, and oxygen therapy, Bi-PAP reduces the work of breathing and improves gas exchange, dyspnea and respiratory distress more effectively $[17,18]$. However, the role of Bi-PAP in patients with ACPE remains controversial. In a comparison of CPAP with Bi-PAP, the latter demonstrated more rapid recovery of respiratory and 
hemodynamic parameters [19], but Bi-PAP associated with an increased incidence of acute myocardial infarction [14]. Recently, Nouira et al., [20] showed that Bi-PAP improves respiratory failure, while, Masip et al., [21] showed a decrease in intubation rate in Bi-PAP group when compared with CPAP. However, other studies [10, 22] failed to demonstrate significant differences in vital signs, blood gases, and rate of myocardial infarction between two modes of ventilations and between Bi-PAPA and oxygen therapy [23]. Moreover, Gray et al., [24] did not find the difference in intubation or mortality rates with either CPAP or Bi-PAP compared to oxygen therapy. In contrast, previous trials [21, 25] found that Bi-PAP reduced the need for invasive mechanical ventilation, and endotracheal intubation when compared with oxygen therapy.

In spite of the potential advantages of NIV for the management of ACPE, there appears to be a lack of highquality clinical evidence to support the use of these interventions. Additionally, there is only one study [26] that investigated the role of NIV on ACPE in emergency departments in Egypt. Therefore, the purpose of this study was to compare the efficacy of CPAP, Bi-PAP, and standard oxygen therapy on detailed observation of time-course change in blood gases and physiological parameters in patients with ACPE. Furthermore, to investigate whether either CPAP or Bi-PAP would cause improvement in endotracheal intubation and death rates.

\section{Material and Methods}

\subsection{Study Design and Participants}

This study was a single blinded, randomized controlled trial with repeated measurement analysis. Patients who attend the emergency department at National Heart Institute, Imbaba, Giza, Egypt, with clinical evidence of ACPE were eligible for enrollment in this study. Inclusion criteria were: severe dyspnea, bilateral rales on auscultation, and typical findings of congestion on chest radiography without evidence of pulmonary aspiration or pneumonia. In addition, respiratory rate of $\geq 30$ breaths per minute, hypoxemia $\left(\mathrm{PaO}_{2}\right.$ $\leq 80 \mathrm{mmHg}$ ) with a fraction of inspired oxygen $\left(\mathrm{FiO}_{2}\right)$ of $60 \%$ via a Venturi mask, and $\mathrm{PaCO}_{2} \geq 45 \mathrm{mmHg}[14,20,27,28]$.

Exclusion criteria were: requirement for a life-saving or emergency intervention, such as primary percutaneous coronary intervention, or chronic obstructive pulmonary diseases, hemodynamic instability (systolic $\mathrm{BP} \leq 90 \mathrm{mmHg}$ ), or life-threatening arrhythmia, acute myocardial infarction and/ or unstable angina, recent facial trauma, and esophageal/gastric surgery, gastrointestinal bleeding, or pregnant $[22,28]$.

Postgraduate ethics committee at faculty of physical therapy, Cairo university approved this study. The trial registration code of this study was ACTRN12614001208695. Depending on the severity of the illness, the patients or their relative gave written informed consent.

The estimated sample size was 60 patients in all groups and would be increased to 69 for possible dropout. This sample size was estimated to detect $5 \mathrm{mmHg}$ difference in $\mathrm{PaCO}_{2}$ among groups; with the probability level was set at 0.05 and power of $80 \%$ [14]. Then, the patients were randomly assigned into CPAP-group $(n=23)$, Bi-PAP-group $(n=23)$ and standard oxygen therapy $\left(\mathrm{O}_{2}\right.$-group $)(n=23)$. Randomization was performed within one hour of arrival using an opaque envelope, which was further concealed within another. Once enrolled within the study it was impossible to mask treatment allocation.

\subsection{Intervention}

All patients received the standard medical treatment, according to the emergency department protocol, at the National Heart Institute [29]. These included: 1) supplementary oxygen therapy was supplied at a rate of up to 15 liters per minute via a reservoir mask to maintain oxygen saturation $\geq 90 \%$; 2) nitroglycerine $0.4 \mathrm{mg}$ sublingual if systolic $\mathrm{BP}>100 \mathrm{mmHg}$-excluding patients receiving potential drug interaction preparations, doses can be repeated every 5 minutes; 3) frusemide IV starts with $40 \mathrm{mg}$ and in incremental doses if required; 4) morphine sulfate $2 \mathrm{mg} \mathrm{IV}$, may be repeated once. If $\mathrm{BP}$ less than $100 \mathrm{mmHg}$ dopamine is given starting at $2.5 \mathrm{mcg} / \mathrm{Kg} / \mathrm{min}$ and increase dose every 10 minutes if BP remains low. Patients were continuously monitored using pulse oximetry, and electrocardiography to detect changes in vital signs. In addition, urinary output was checked using a Foley's catheter.

NIV was delivered through a full-face mask by a Respironics Synchrony ventilator (Model RTX Inodes, 10 Downage RespiCare, Drager, London). In the CPAP group, a continuous pressure of $10 \mathrm{cmH}_{2} \mathrm{O}$ was generated. Patients in Bi-PAP group received IPAP $\left(15 \mathrm{cmH}_{2} \mathrm{O}\right)$ and EPAP $\left(5 \mathrm{cmH}_{2} \mathrm{O}\right)[10,13,14]$. All patients received their assigned treatment for 1 hour. After NIV mask removed, the patients continued to receive standard $\mathrm{O}_{2}$ facemask.

Criteria for termination of noninvasive ventilation therapy were: inability to tolerate the tightness of the mask or pressure, abundant secretion or met the criteria for intubation according to Brochard et al [30]. In those who could not tolerate the NIV, it was stopped and standard facemask $\mathrm{O}_{2}$ applied. After the study period (90 minutes), the patients were transferred to medical ward or admitted to an intensive care unit (ICU) if they required intubation or did not improve.

\subsection{Outcome Measures}

The primary outcome measures were physiological parameters concerning blood gases $\left(\mathrm{PaCO}_{2}, \mathrm{PaO}_{2}, \mathrm{SaO}_{2}, \mathrm{pH}\right.$, and $\mathrm{HCO}_{3}$ ), and physiological parameters (HR, RR, SBP, and DBP). These parameters were collected before entry of the study (T0), after 60 minutes (T60), of NIV application and after 30 minutes (T90) of NIV discontinuation. Secondary outcomes were rate of endotracheal intubation, and the rate of death that reported at the time of discharge. Therapist recorded the adverse events of NIV (mucosal pain, nasal 
bridge erythema, or ulcerations, eye irritation, vomiting \& gastric distension) during applications.

Blinded laboratory investigator drawn blood samples through an arterial cannula from radial artery using heparin rinsed plastic syringe, then analyzed it immediately using the acid-base analyzer (Model ABL 3075R 24NB, and Manufactured by Radiometer $\mathrm{A} / \mathrm{S}$ Copenhagen) to detect the level of $\left(\mathrm{PaO}_{2}, \mathrm{PaCO}_{2}, \mathrm{pH}, \mathrm{HCO}_{3}\right.$ and $\left.\mathrm{SaO}_{2}\right)$.

\subsection{Statistical Analysis}

Statistical analyses were performed using the Statistical Package for the Social Sciences (SPSS) version 21.0. Kolmogorov-Smirnov test was used to determine the normality of data distribution. Normally distributed data were described as mean and standard deviation; otherwise, the data were presented as frequency, median and range and analyzed non-parametrically. A one way repeated measure analysis of variance (ANOVA), with the Scheffe test for repeated comparison was used to identify specific differences within and between groups at each time point. Variables without normal distribution and homogeneous variance were analyzed with the Kruskal-Wallis test. All statistical analysis was two-tailed with significant differences was assumed at $\mathrm{p}<0.05$.

\section{Results}

\subsection{Baseline Demographic and Clinical Characteristics of the Patients}

Figure 1 shows the flow chart of patient enrollment. 105 patients with acute pulmonary edema were admitted to the emergency department at National Heart Institute, Giza, Egypt, from May 2007- to November 2008. Among those, 69 patients were met the inclusion/exclusion criteria; three patients were excluded (two on CPAP-group, and one on BiPAP-group). Therefore, 66 patients $(27$ males and 39 females) completed the study procedures and were included in the final analysis.

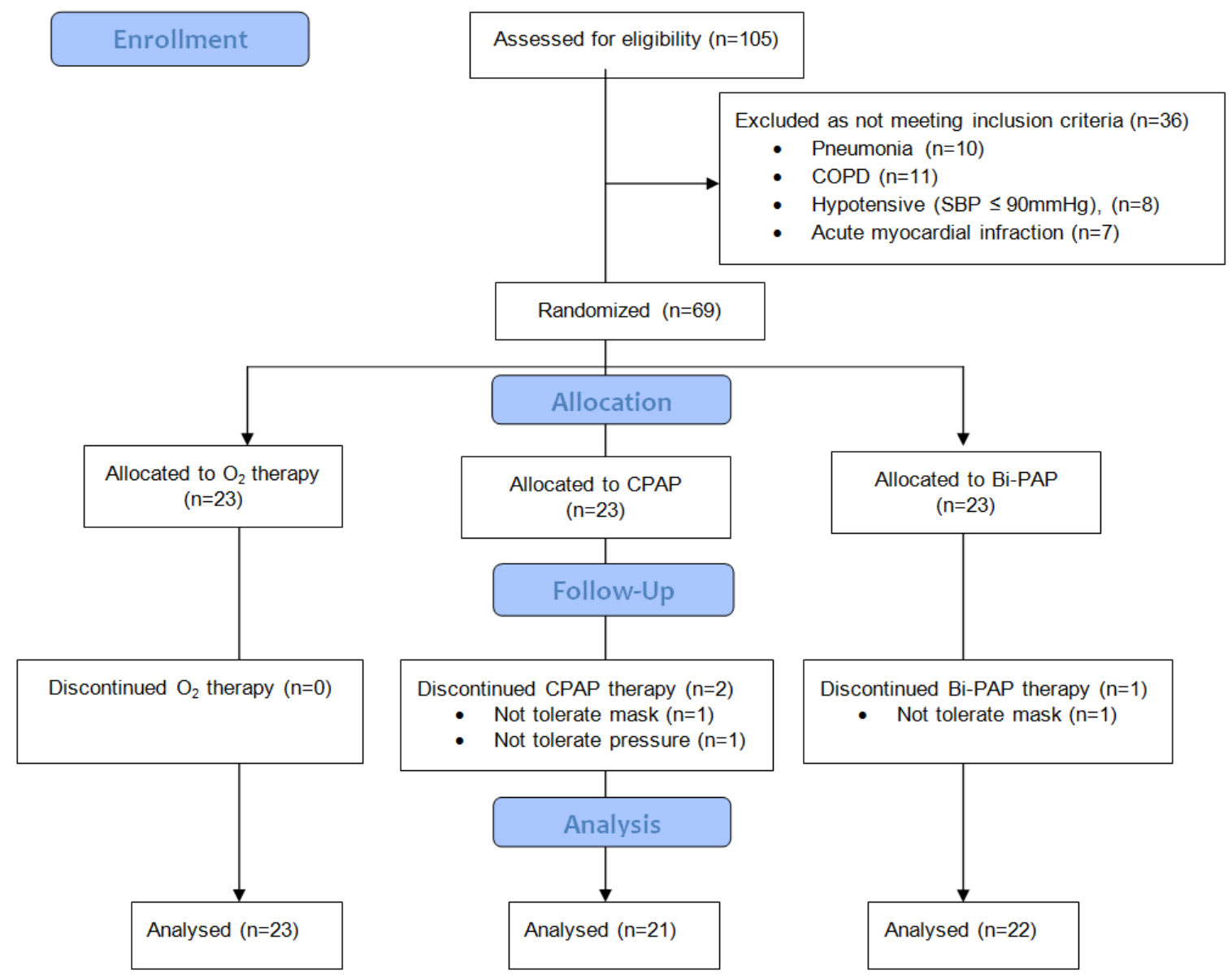

Figure 1. Flow of participants through the study.

Table 1 represents the baseline demographic and clinical characteristics of all patients. All groups were comparable in baseline characteristics ( $\mathrm{P}>0.05)$ and physiological measurements ( $p>0.05)$. Pulmonary edema was confirmed in all patients by portable radiography, and developed secondary to ischemic cardiomyopathy, 37 patients $(56 \%)$ or dilated cardiomyopathy, 29 patients (44\%). Adverse events such as mucosal pain, nasal bridge ulcerations, eye irritation, vomiting \& gastric distension were not reported during applications of NIV. Only mild nasal bridge rednish was 
observed in 10 patients, 6 in CPAP group and 4 in Bi-PAP group.

Table 1. Baseline demographic and clinical characteristics of three treatment groups.

\begin{tabular}{|c|c|c|c|}
\hline \multirow[b]{2}{*}{ Variables } & \multicolumn{3}{|c|}{ Treatment Groups } \\
\hline & $\begin{array}{l}\text { Control } \\
(n=23)\end{array}$ & $\begin{array}{l}\text { CPAP } \\
(n=21)\end{array}$ & $\begin{array}{l}\text { Bi-PAP } \\
(n=22)\end{array}$ \\
\hline Age (years) & $57 \pm 5.3$ & $58.4 \pm 6.53$ & $56.6 \pm 5.12$ \\
\hline \multicolumn{4}{|l|}{ Genders n (\%) } \\
\hline Males & $9(39.1 \%)$ & $8(38.1 \%)$ & $10(45.45 \%)$ \\
\hline Females & $14(60.9 \%)$ & $13(61.9 \%)$ & $12(54.54 \%)$ \\
\hline \multicolumn{4}{|l|}{ Etiology of ACPE n (\%) } \\
\hline Ischemic cardiomyopathy & $13(56.53 \%)$ & $12(57.14 \%)$ & $12(54.54 \%)$ \\
\hline Dilated cardiomyopathy & $10(43.47 \%)$ & $9(42.86 \%)$ & $10(45.45 \%)$ \\
\hline \multicolumn{4}{|l|}{$\begin{array}{l}\text { Physiological } \\
\text { measurements }\end{array}$} \\
\hline $\mathrm{HR}(\mathrm{bpm})$ & $127 \pm 9.51$ & $123 \pm 17.21$ & $127 \pm 9.82$ \\
\hline RR (brpm) & $38 \pm 3.04$ & $38 \pm 5.8$ & $36 \pm 4.98$ \\
\hline $\mathrm{SBP}(\mathrm{mmHg})$ & $150 \pm 12.01$ & $149 \pm 9.3$ & $147 \pm 8.01$ \\
\hline DBP (mmHg) & $99 \pm 11.57$ & $94 \pm 9.98$ & $94 \pm 9.63$ \\
\hline $\mathrm{PaO} 2$ (mmHg) & $67.75 \pm 5.3$ & $64.04 \pm 6.83$ & $63.83 \pm 7.23$ \\
\hline $\mathrm{PaCO} 2(\mathrm{mmHg})$ & $48.22 \pm 1.86$ & $48.05 \pm 2.77$ & $49.23 \pm 3.21$ \\
\hline $\mathrm{SaO} 2(\%)$ & $86.15 \pm 3.88$ & $88.14 \pm 3.19$ & $86.23 \pm 4.94$ \\
\hline $\mathrm{HCO} 3(\mathrm{mmol} / \mathrm{l})$ & $22.57 \pm 2.5$ & $22.95 \pm 2.71$ & $22.45 \pm 2.27$ \\
\hline $\mathrm{pH}$ & $7.4 \pm 0.03$ & $7.39 \pm 0.02$ & $7.38 \pm 0.05$ \\
\hline \multicolumn{4}{|l|}{$\begin{array}{l}\text { Medical treatment-n }(\%) \text { of } \\
\text { patients }\end{array}$} \\
\hline Vasodilators & $23(100 \%)$ & $20(95 \%)$ & $20(91 \%)$ \\
\hline Diuretics & $23(100 \%)$ & $21(100 \%)$ & $22(100 \%)$ \\
\hline Opioids & $13(56.5 \%)$ & $11(52.38 \%)$ & $12(54.5 \%)$ \\
\hline Inotropic & $2(8.7 \%)$ & $2(9.5 \%)$ & $2(9 \%)$ \\
\hline
\end{tabular}

$\mathrm{Bi}-\mathrm{PAP}=\mathrm{Bi}-$ Level Positive Airway Pressure, $\mathrm{bpm}=$ Beat per minute, $\mathrm{brpm}=$ Breath per minute $\mathrm{CPAP}=$ Continuous Positive Airway Pressure, DSP $=$ Diastolic blood pressure, $\left(\mathrm{HCO}_{3}\right)=$ Arterial Blood Bicarbonate, $\mathrm{HR}=$ Heart rate, $\left(\mathrm{PaCO}_{2}\right)=$ Arterial Carbon Dioxide Pressure, $\left(\mathrm{PaO}_{2}\right)=$ Arterial Oxygen Pressure, $(\mathrm{pH})=$ Hydrogen Ion Concentration, $\mathrm{mmHg}=$ Millimeter mercury pressure, $\mathrm{mmol} / \mathrm{L}=$ Milmole per liter, $\mathrm{RR}=$ Respiratory rate, $\left(\mathrm{SaO}_{2}\right)=$ Oxygen Saturation, $\mathrm{SBP}=$ Systolic blood pressure, $\%=$ Percentage, ${ }^{\overline{\mathrm{T}}}=$ significant differences $(p<0.05)$ among the three groups.

\subsection{Primary Outcomes}

Table 2 shows physiological measurements during the study periods. The mean values of $\mathrm{PaO}_{2}$ and $\mathrm{SaO}_{2}$ were significantly increased in CPAP and Bi-PAP groups compared to oxygen therapy after 60 minutes of intervention (T60). After 30 minutes of discontinuation (T90) of intervention, the mean values of $\mathrm{PaO}_{2}$ and $\mathrm{SaO}_{2}$ were significantly lowered in CPAP and Bi-PAP groups compared to 60 minutes of intervention, except for for oxygen therapy, there were non-significant increase in $\mathrm{PaO}_{2}$ and $\mathrm{SaO}_{2}$ compared to 60 minutes of intervention. However, the $\mathrm{Bi}$ PAP-group remained had significantly increased in $\mathrm{PaO}_{2}$ and $\mathrm{SaO}_{2}$ compared to oxygen therapy $(86.75 \pm 6.51 \mathrm{vs} 80.6 \pm 8.09$, $\mathrm{P}<0.05$ and $94.47 \pm 2.96$ vs92.05 $\pm 1.96, \mathrm{P}<0.05)$ and CPAPgroup $(86.75 \pm 6.51$ vs $75.57 \pm 6.47 \pm 6.47, \quad \mathrm{P}<0.01$ and $94.47 \pm 2.96$ vs $89.94 \pm 3.72, \mathrm{P}<0.01)$, respectively.

The percentage increase of $\mathrm{PaO}_{2}$, and $\mathrm{SaO}_{2}$ was primarily higher in Bi-PAP-group (81.76\% and $14.18 \%$ ) compared to CPAP-group (72.25\% and $10.77 \%)$ and oxygen therapy $(7.13 \%$ and $1.98 \%)$ immediately after 60minutes of intervention (T60). While after 30 minutes of discontinuation (T90), percentage increase of $\mathrm{PaO}_{2}$, and $\mathrm{SaO}_{2}$ was predominately in the oxygen therapy $(19.97 \%$ and $6.85 \%$ ), while for CPAP and Bi-PAP groups, the percentages decreased to $(18 \%, 35.9 \%$ and $2.04 \%, 9.56 \%)$ respectively.

Table 2. Blood gases measurements during 90 minutes of study period in three groups.

\begin{tabular}{|c|c|c|c|}
\hline & \multicolumn{3}{|c|}{ Study Period Measurements } \\
\hline & Baseline(T0) & 60 minutes(T60) & 90 minutes(T90) \\
\hline \multicolumn{4}{|c|}{$\mathrm{PaO}_{2}(\mathrm{mmHg})$} \\
\hline Control & $67.75 \pm 5.3$ & $72.58 \pm 5.75$ & $80.6 \pm 8.09^{*}$ \\
\hline CPAP & $64.04 \pm 6.83$ & $110.31 \pm 25.61^{* \bar{\top}}$ & $75.57 \pm 6.47$ \\
\hline Bi-PAP & $63.83 \pm 7.23$ & $116.02 \pm 23.96^{* \bar{\top}}$ & $86.75 \pm 6.51^{* \bar{\top}}$ \\
\hline \multicolumn{4}{|c|}{$\mathrm{PaCO}_{2}(\mathrm{mmHg})$} \\
\hline Control & $48.22 \pm 1.86$ & $47.01 \pm 3.26$ & $46.43 \pm 2.01$ \\
\hline CPAP & $48.05 \pm 2.77$ & $42.39 \pm 3.68^{* \bar{\top}}$ & $40.34 \pm 2.33^{* \bar{\top}}$ \\
\hline Bi-PAP & $49.23 \pm 3.21$ & $42.21 \pm 5.67^{* \bar{\top}}$ & $38.66 \pm 2.88^{* \bar{\top}}$ \\
\hline \multicolumn{4}{|l|}{$\mathrm{SaO}_{2}$} \\
\hline Control & $86.15 \pm 3.88$ & $87.86 \pm 3.63$ & $92.05 \pm 1.96^{*}$ \\
\hline CPAP & $88.14 \pm 3.19$ & $97.63 \pm 1.44^{* \bar{\top}}$ & $89.94 \pm 3.72$ \\
\hline Bi-PAP & $86.23 \pm 4.94$ & $98.46 \pm 2.8^{* \bar{\top}}$ & $94.47 \pm 2.96^{* \bar{\top}}$ \\
\hline \multicolumn{4}{|l|}{$\mathrm{pH}$} \\
\hline Control & $7.4 \pm 0.03$ & $7.41 \pm 0.02$ & $7.42 \pm 0.03$ \\
\hline CPAP & $7.39 \pm 0.02$ & $7.4 \pm 0.03$ & $7.41 \pm 0.03$ \\
\hline Bi-PAP & $7.38 \pm 0.05$ & $7.4 \pm 0.04$ & $7.41 \pm 0.04$ \\
\hline \multicolumn{4}{|c|}{$\mathrm{HCO}_{3}(\mathrm{mmoL} / \mathrm{L})$} \\
\hline Control & $22.57 \pm 2.52$ & $23.28 \pm 3.55$ & $24.03 \pm 1.91$ \\
\hline CPAP & $22.95 \pm 2.71$ & $23.99 \pm 3.01$ & $24.44 \pm 2.8$ \\
\hline Bi-PAP & $22.45 \pm 2.27$ & $23.19 \pm 3.22$ & $23.93 \pm 2.53$ \\
\hline
\end{tabular}

Bi-PAP $=$ Bi-Level Positive Airway Pressure, $\mathrm{CPAP}=$ Continuous Positive Airway Pressure, $\left(\mathrm{HCO}_{3}\right)=$ Arterial Blood Bicarbonate, $\left(\mathrm{PaCO}_{2}\right)=$ Arterial Carbon Dioxide Pressure, $\left(\mathrm{PaO}_{2}\right)=$ Arterial Oxygen Pressure, $(\mathrm{pH})=$ Hydrogen Ion Concentration, $\mathrm{mmHg}=$ Millimeter mercury pressure, $\mathrm{mmol} / \mathrm{L}=$ Milmole per liter, $\left(\mathrm{SaO}_{2}\right)=$ Oxygen Saturation,. ${ }^{*}=$ significant differences $(p<0.05)$ within group compared to baseline. ${ }^{\bar{\top}}=$ significant differences $(\mathrm{p}<0.05)$ between groups compared to control group.

The $\mathrm{PaCO}_{2}$ was significant $(\mathrm{P}<0.01)$ lower in CPAP and $\mathrm{Bi}$-PAP groups compared to the oxygen therapy group with no differences between CPAP and Bi-PAP groups through the study period. There no difference between the three groups, regards to $\mathrm{HCO}_{3}$ and at any other time point.

As presented in (Figures 2 and 3), time-related changes in heart rate, respiratory rate, and blood pressure were significantly $(\mathrm{p}<0.01)$ lowered in CPAP and Bi-PAP groups at each time point compared to baseline. In the Oxygen therapy group, there were no significant differences in heart rate, and respiratory rate. However, significant differences were detected in blood pressure after 30 minutes of discontinuation of intervention (T90).

Group-related differences showed statistically significant $(\mathrm{P}<0.01)$ differences in percentage of reductions in the heart rate $(22.33 \%$, versus $10.26 \%$ and $3.14 \%, \mathrm{p}=0.05)$, respiratory rate $(29.86 \%$, versus $25.23 \%$ and $4.63 \%, \mathrm{P}=$ 0.05 ), for Bi-PAP group compared to the CPAP and oxygen therapy respectively, after 60 minutes (T60) of intervention. Except for systolic blood pressure and diastolic blood pressure significant differences detected between Bi-PAP- 
group compared to oxygen therapy (SBP: $19.73 \%$ versus $5.32 \%, \mathrm{p}>0.05$ and DBP; $14.86 \%$ versus $6.1 \%, \mathrm{P}>0.05$ ), However, no significant differences detected between $\mathrm{Bi}$ PAP-group and CPAP-group (SBP: $19.73 \%$ versus 15.05\%, $\mathrm{p}>0.05$ and DBP; $14.86 \%$ versus $10.93 \%, \mathrm{P}>0.05$ ) after 60 minutes of interventions. The percentage of reduction in physiological parameters observed after 30minutes of therapy discontinuation revealed a continuous and greater percentage of reduction in Bi-PAP-group (26.69\% versus $14.85 \%$, and
$3.93 \%)$, for heart rate, $(36.25 \%$ versus $30.72 \%$, and $5.31 \%$ ) for respiratory rate compared to CPAP-group and oxygen therapy. There were no significant differences detected between Bi-PAP and CPAP groups regards to systolic blood pressure $(22.1 \%$ versus $20.4 \%, \mathrm{p}>0.05)$ and diastolic blood pressure, $(16.71 \%$ versus $13.87 \%$, $\mathrm{p}>0.05)$. However, marked significant differences were observed between both Bi-PAP and CPAP groups compared to oxygen therapy.
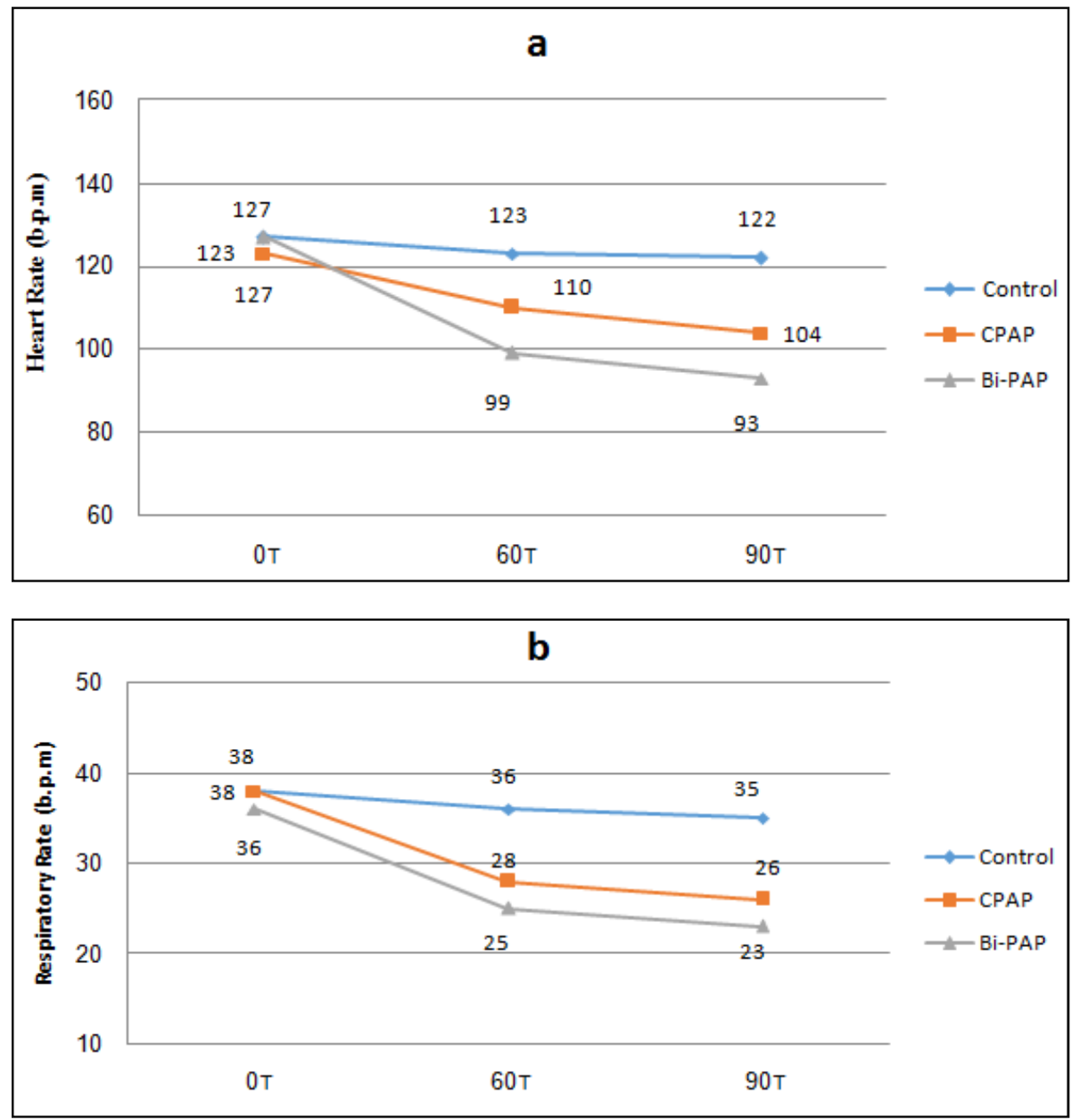

Figure 2. Changes in physiological parameters heart rate (a) and respiratory rate (b) at baseline of study (T0), after 60 minutes of intervention (T60) and after 30 minutes (T90) of discontinuation of intervention for Bi-PAP, CPAP, and Oxygen therapy groups.

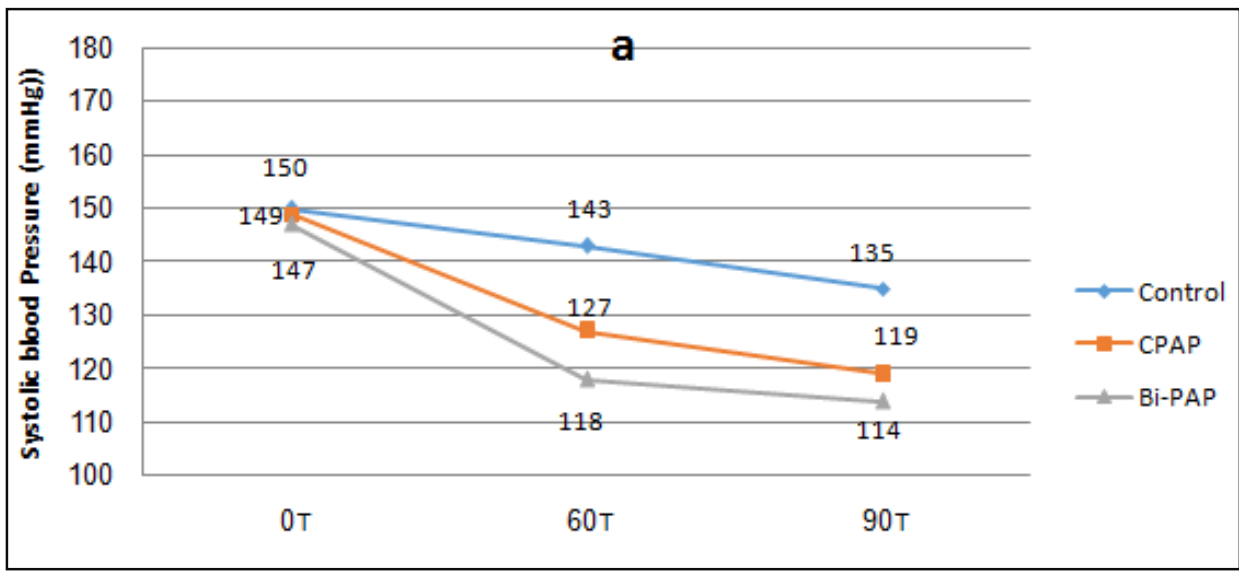




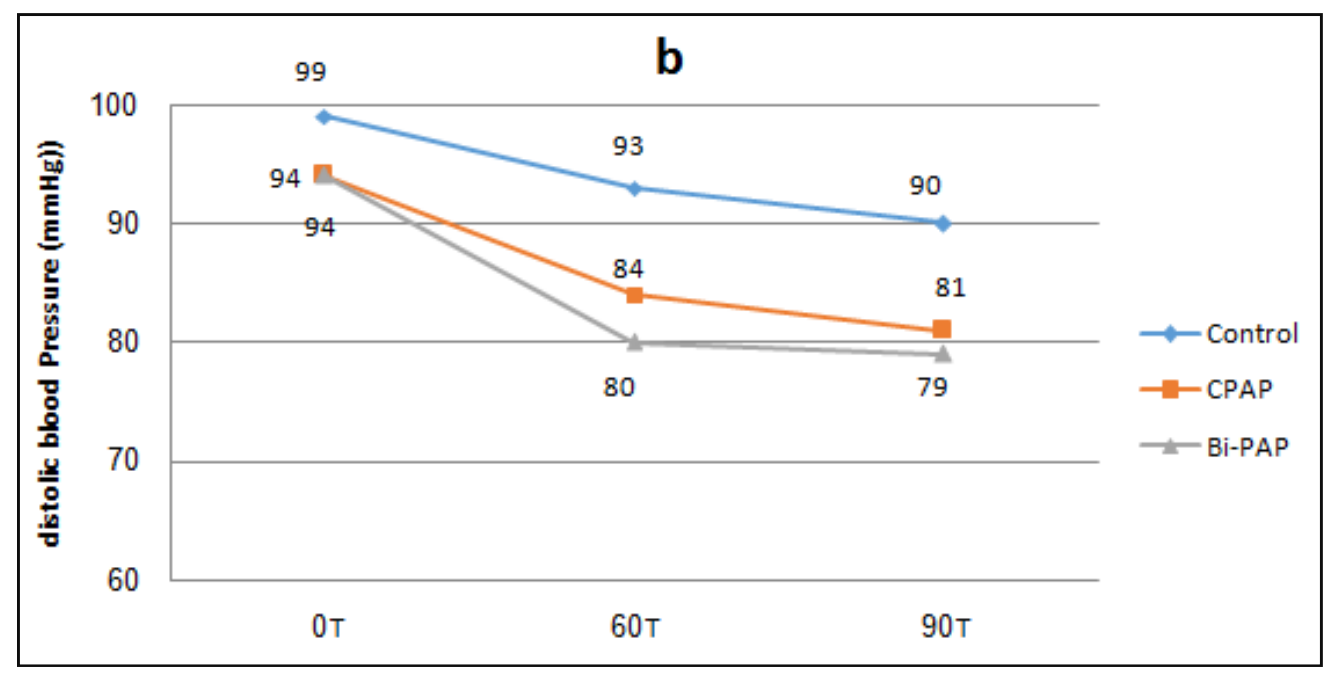

Figure 3. Changes in physiological parameters systolic and diastolic blood pressure (SBP-a) and (DBP-b) at baseline of study (T0), after 60 minutes of intervention (T60) and after 30 minutes (T90) of discontinuation of intervention for Bi-PAP, CPAP, and Oxygen therapy Groups..

\subsection{Secondary Outcomes}

There was no significant difference in the hospital death, and intubations rates between both Bi-PAP and CPAP groups compared to oxygen therapy. As $22(95 \%)$ of the control group patients survived to hospital discharge (one patient died due to ventricular dysrhythmias), compared with $21(100 \%)$ in the CPAP group and $22(100 \%)$ in the Bi-PAPgroup. There was no difference in hospital stay among groups and all patients discharged within 24 hours after the study. However, one patient (4.3\%) was intubated because of worsening of gas exchange in the control group.

\section{Discussion}

To our knowledge, this study is the first single blinded, randomized trial designed to compare the potential effectiveness of Bi-PAP, CPAP and standard oxygen therapy on blood gases and physiological parameters in patients with ACPE at the emergency department in Egypt. In addition, this study investigates whether there was a difference between Bi-PAP and CPAP with regrading rate of endotracheal intubation, and the rate of death reported at the time of discharge.

In this study, the effects of CPAP and Bi-PAP were superior to the oxygen therapy group regarding improvement of blood gases $\left(\mathrm{PaO}_{2}, \mathrm{PaCO}_{2}\right.$ and $\left.\mathrm{SaO}_{2}\right)$ and physiological parameters (HR, RR, SBP, and DBP). The effects of Bi-PAP and CPAP were similar except_in heart rate and respiratory rate within 60 minutes of application. In addition, patients receiving Bi-PAP had significant improvement in $\mathrm{PaO}_{2}$, $\mathrm{SaO}_{2}$, and $\mathrm{HR}$ and $\mathrm{RR}$ within 90 minutes of initiation of therapy. These physiologic benefits did not accompany by a difference in endotracheal intubation and death rates $(\mathrm{P}>$ $0.05)$ among groups. There were no serious adverse effects related to application of CPAP or Bi-PAP.

The results of current study are supported by several studies $[9,21,24]$. The authors revealed that, both Bi-PAP and CPAP had marked effect when compared with standardized oxygen therapy regarding gas exchange, and heart rate, with no adverse events. However, Gray et al., [24] did not report significant differences between NIV compared to standard oxygen therapy regarding to RR, SBP, and DBP. This may be due to differences in the values of applied pressure and in patient characteristics.

The current significant reduction in RR observed in $\mathrm{Bi}$ PAP group compared to CPAP group might be attributed to the effect of Bi-PAP in unloading respiratory muscles. This agrees with finding of Chadda et al., [17] who concluded that, addition of a pressure-supported ventilation of Bi-PAP might improve the respiratory pump, and alveolar ventilation leading to rapid reduction in respiratory rate than with CPAP alone. Similarly, Nouria and colleagues [20] reported significant increase in $\mathrm{PaO}_{2}$ and decrease in $\mathrm{HR}$, and $\mathrm{RR}$ in both Bi-PAP and CPAP groups. However, Bi-PAP accelerated the improvement of respiratory failure compared to CPAP.

An improvement in RR and symptoms of respiratory fatigue (improved breathing pattern, decreasing intercostal suprasternal retraction and subjective respiratory distressed) when coupled with improved oxygenation, and lower $\mathrm{PaCO}_{2}$ is considered as indirect objective evidence of decrease work of breathing, dyspnea, and alveolar hypoventilation [15, 31]. These confirm that the therapeutic intervention in our study was delivered successfully and appropriately.

In contrast to our findings, Levitt [23] demonstrate no significant effect of Bi-PAP compared to oxygen therapy on vital signs, blood gases. These results may be attributed to the low pressure applied and baseline differences between the groups. Our study failed to show a major difference to improve blood gases between CPAP and Bi-PAP techniques within 60 minutes of application. These findings are in agreement with those reported in previous studies [10-12, 20, 28, 32-34] In addition, there was an apparent drop in the $\mathrm{PaO}_{2}$ and $\mathrm{SaO}_{2}$ after 30 minutes of discontinuation of NIV. This drop was significant in CPAP compared to Bi-PAP group. There is no treatment failure attributed to worsening 
hypoxia and the improvement in the Bi-PAP group might produce faster than CPAP group. These findings showed that, the changes in blood gases were owing to the effect of NIV rather than other factors such as medication.

Our results showed no difference in the proportion of patients who underwent endotracheal intubation and the rate of death among groups. These results were similar to previous studies [24, 35]. Moreover, systematic review and meta-analysis conducted by Hui et al., [36] reported no differences in mortality, intubation rate, and length of stay in the hospital between Bi-PAP and CPAP. However, some studies $[33,37]$ reported $(47 \%)$ reduction in mortality rate [33] and no endotracheal intubation [37] among ACPE patient who treated with NIV.

Contrast, to our findings Mehta et al., [14] prematurely completed their trial comparing CPAP with Bi-PAP because of increased rate of MI and mortality in Bi-PAP group, with higher incidence of chest pain in Bi-PAP group at the entry of the study which suggested non-homogeneity between the groups.

The specific pressure values of CPAP and Bi-PAP in this study selected based on previous studies [10, 13, 14, 38]. This pressure $\left(15 / 5 \mathrm{Cm} \mathrm{H}_{2} \mathrm{O}\right)$ of $\mathrm{Bi}-\mathrm{PAP}$ provided mean airway pressures close to those levels obtained with a CPAP of $10 \mathrm{Cm}$ $\mathrm{H}_{2} \mathrm{O}$, although we cannot be sure that intrathoracic pressures result from these selected pressure values would be similar.

The limitations of this study were; the physicians who decided when it started endotracheal intubation or to cease NIV were not blinded .This increase the possibility of a bias, however, blinding in our study was not feasible; Further NIV studies should consider blinding physician to the mode of NPPV used. Moreover, small sample size, and long-term results are not available, so additional large international Multicenter study comparing three treatment arms is required to investigate long-term improvement.

\section{Conclusion}

Both CPAP and Bi-PAP are safe, well-tolerated adjunctive therapy in patients with ACPE. The Bi-PAP therapy had faster and continuous improvement in RR, with rapid improvement in $\mathrm{PaO}_{2}$ and $\mathrm{SaO}_{2}$ compared to both CPAP and standardized oxygen therapy. However, there were similar reductions in death and intubation rates among groups. Because of its immediate efficacy, and lack of serious side effects, Bi-PAP should be encouraged as a first-line therapy in a patient with ACPE in emergency setting.

\section{References}

[1] Felker GM, Adams KF Jr, Konstam MA, et al. The problem of decompensated heart failure: nomenclature, classification, and risk stratification. Am Heart J 2003; 145: Suppl: S18-S25.

[2] Girou E, Brun-Buisson C, Taillé S, et al. Secular trends in nosocomial infections and mortality associated with noninvasive ventilation in patients with exacerbation of COPD and pulmonary edema. JAMA 2003; 290: 2985-91.
[3] Stevenson R, Ranjadayalan K, Wilkinson P, et al. Short and long term prognosis of acute myocardial infarction since introduction of thrombolysis. BMJ 1993; 307: 349-53. [Erratum, BMJ 1993; 307: 909.]

[4] Pingleton SK: Complication of acute respiratory failure. Am Rev Respir Dis 1988, 173: 1463-1493.

[5] Baratz DM, Westbrook PR, Shah PK, et al. Effect of nasal continuous positive airway pressure on cardiac output and oxygen delivery in patients with congestive heart failure. Chest 1992; 102: 1397-401.

[6] Lenique F, Habis M, Lofaso F, et al. Ventilatory and hemodynamic effects of continuous positive airway pressure in left heart failure. Am J Respir Crit Care Med 1997; 155: 500-5.

[7] Naughton MT, Rahman MA, Hara K, et al. Effect of continuous positive airway pressure on intrathoracic and left ventricular transmural pressures in patients with congestive heart failure. Circulation 1995; 91: 1725-31.

[8] Park M, Lorenzi-Filho G, Feltrim MI, et al. Oxygen therapy, continuous positive airway pressure, or noninvasive bilevel positive pressure ventilation in the treatment of acute cardiogenic pulmonary edema. Arq Bras Cardiol 2001; 76: 221-30.

[9] Park M, Sangean MC, Volpe MS, et al. Randomized, Prospective Trial of Oxygen Therapy, Continuous Positive Airway Pressure, and Bi-level Positive by Face Mask in Acute Cardiogenic Pulmonary Edema. Crti Care Med. 2004; 32: 2407-15.

[10] Bellone A, Monari A, Cortellaro F, et al. "Myocardial Infarction Rate in Acute Pulmonary Edema: Non-Invasive Pressure Support Ventilation Versus Continuous Positive Airway Pressure" Intensive Care Med. 2004; 32: 1860-1865.

[11] Moritz F, Brousse B, Gelle'e B, et al. Continuous Positive Airway Pressure versus Bi-level Noninvasive Ventilation in Acute Cardiogenic Pulmonary Edema: a Randomized Multicenter Trial" Ann Emerg Med. 2007; 50 (6): 666-675.

[12] L'Her E, Duquesne F, Girou E, et al. Noninvasive Continuous Positive Airway Pressure in elderly Cardiogenic pulmonary Edema Patients. Intensive Care Med. 2004; 30: 882-888.

[13] Crane SD, Ellitto MW, Gilligan P, et al. Randomized Controlled Comparison of Continuous Positive Airway pressure, Bi-level Non-Invasive Ventilation, and standard treatment in Emergency Department patients with Acute Cardiogenic Pulmonary Edema. Emerg Med J. 2004; 21: 155161.

[14] Mehta S., Jay GD., Woolard RH., et al. Randomized, Prospective Trial of Bi-level Versus Continuous Positive Airway Pressure in Acute Pulmonary Edema. Crit Care Med. 1997; 25: 620-628.

[15] Bersten AD, Holt AW, Vedig AE, et al. Treatment of Sever Cardiopulmonary Edema Continuous Positive Airway Pressure Delivered by Face Mask. N Engl J Med. 1991; 325: 1825-30.

[16] Lin M, yang Y, Chiang HT, et al. Reappraisal of Continuous Positive Airway Pressure Therapy in Acute Cardiogenic Pulmonary Edema. Chest. 1995; 107: 1379-1386. 
[17] Chadda K, Annane D, Hart N, et al. Cardiac and Respiratory Effects of Continuous Positive Airway Pressure and Noninvasive Ventilation in Acute Cardiopulmonary Edema. Crit Care Med. 2002; 30: 2457-2461.

[18] Nava S, Carbone G, Dibattista N, et al. Noninvasive Ventilation in Cardiogenic Pulmonary Edema: a Multicenter Randomized Trial. Am J Respir Crit Care Med. 2003; 168: 1432-1437.

[19] Lin M, Chiang H. The efficacy of early continuous positive airway pressure therapy in patients with acute cardiogenic pulmonary edema. Journal of the Formosan Medical Association 1991; 90 (8): 736-43.

[20] Nouira S, Boukef R, Bouida W, et al. Noninvasive pressure support ventilation and CPAP in cardiogenic pulmonary edema: a multicenter randomized study in the emergency department. Intensive Care Med 2011; 37: 249-56.

[21] Masip J, Betbese AJ, Paez J, et al. Non-Invasive Pressure Support Ventilation Versus Conventional Oxygen Therapy in Acute Cardiogenic Pulmonary Oedema: A Randomized Trial. Lance. 2000; 356: 2126-32.

[22] Ferrari G, Olliveri F, De Filippi G, et al. Noninvasive Positive Airway Pressure and Risk of Myocardial Infarction in Acute Cardiogenic Pulmonary Edema: Continuous Positive Airway Pressure vs Noninvasive Positive Pressure Ventilation. Chest. 2007; 132 (6): 1804-1809.

[23] Levitt MA. A Prospective, Randomized Trial of Bi-PAP in Severe Acute Congestive Heart Failure. J Emerg Med. 2001; 21(4): 363-369.

[24] Gray A, Goodscre S, Newby DE, et al. 3COP Trailists. Noninvasive Ventilation in Acute Cardiogneic Pulmonary Edema. N Engl J Med. 2008; 359 (2): 142-151.

[25] Ferrer M, Esquinas AN, Leon M, et al. Noninvasive Ventilation in Severe Hypoxemic Respiratory Failure: a Randomized Clinical Trial. Am J Respir Crit Care Med. 2003; 168 (12): 1438-1444

[26] Hasan BE, Elwela GM, Bondok RH, et al., Noninvasive BiPAP Ventilation For acute cardiogenic pulmonary edema. Ain Shamis journal of anastheiology. 2009; 2: 29-38.

[27] Ferrari G, Milan A, Groff P, et al. Continuous Positive Airway Pressure vs. Pressure Support Ventilation in Acute Cardiogenic Pulmonary Edema: A randomized Trial. J Emerg Med. 2009; 70: 042.

[28] Bellone A, Vettorello M, Monari A, et al. Noninvasive
Pressure Support Ventilation vs. Continuous Positive Airway Pressure in Acute Hypercapnic Pulmonary Edema. Intensive Care Med. 2005; 31 (6): 807-811.

[29] Bristow MR, David Port J, and Kelly RA. Treatment of heart failure-Pharmacological methods. In: Braunwald E, editor. A Textbook of Cardiovacular Medicine. 6th ed. Philadelphia 2001. P682-689.

[30] Brochard L, Mancebo J, Wysocki M, et al. Noninvasive ventilation for acute exacerbations of chronic obstruction lung disease. N Engl J Med 1995, 333: 817-22.

[31] Kelly CA, Newb DE, Mc-Donagh TA, et al. Randomized Controlled Trial of Continuous Positive Airway Pressure and Standard oxygen Therapy in Acute Pulmonary Edema. Eur Heart J. 2002; 23: 1379-1386.

[32] Peter JV, Moran JG, Graham P, et al. Effect of Nom -Invasive Positive Pressure Ventilation (NIPPV) on Mortality in Patients with Acute Cardiogenic Pulmonary Edema: A Meta-Analysis. Lancet. 2006; 367: 1155-63.

[33] Masip J, Roque M, Sanchez B, Fernoridez R, et al. Noninvasive Ventilation in Acute Cardiogenic Pulmonary Edema: Systemic Review and Met-Analysis. JAMA. 2005; 294: $3124-30$

[34] Cross AM, Cameron P, Kierce M, et al. Non-invasive Ventilation in Acute Respiratory Failure: a Randomized Comparison of Continuous Positive Airway Pressure and Bilevel Positive Airway Pressure. Emerg Med J. 2003; 20 (6): 531-534.

[35] Liesching T, Nelson DL, Comier KL, et al. Randomized trial of Bilevel versus continuous positive Airway Pressuer for Acute Pulmonary Edema. The Journal of Emergency Medicine. 2014; 46 (1): 130-140.

[36] Hui L, Chunlin H, Jinming X, et al. A comparison of bi-level and continuous positive airway pressure noninvasive ventilation in acute cardiogenic pulmonary edema: A MetaAnalysis. American Journal of Emergency Medicine. 2013; 31: 1322-1327

[37] Garrote JI, Aylagas D, Gutierrez JM, et al. Noninvasive Mechanical Ventilation in Helicopter Emergency Medical Services Save Time and Oxygen and Improves Patient and Mission Safety: A Pilot Study. amj. 2015; 34 (4): 218-222.

[38] Ho KM, and Wong K. A Comparison of Continuous and Bilevel Positive Non-Invasive Ventilation in Patients with Acute Cardiogenic Pulmonary Edema: A Meta-Analysis. Crit Care. 2006; 10 (2): R49. 